\title{
Progression of Pulmonary Function and Correlation with Survival Following Stereotactic Body Radiotherapy of Central and Ultracentral Lung Tumors
}

\author{
Sebastian Regnery 1,2,3, Tanja Eichkorn 1,2,3, Fabian Weykamp 1,2,3 , Thomas Held 1,2,3 (D), \\ Lisa-Antonia Dinges 1,2,3, Fabian Schunn 1,2,3 , Hauke Winter ${ }^{3,4,5}$, Michael Thomas ${ }^{3,5,6}$, \\ Jürgen Debus ${ }^{1,2,3,7,8}$, Rami A. El Shafie ${ }^{1,2,3} \mathbb{D}$, Sebastian Adeberg ${ }^{1,2,3} \mathbb{D}$ and \\ Juliane Hörner-Rieber 1,2,3,8,* \\ 1 Department of Radiation Oncology, Heidelberg University Hospital, Im Neuenheimer Feld 400, \\ 69120 Heidelberg, Germany; sebastian.regnery@med.uni-heidelberg.de (S.R.); \\ tanja.eichkorn@med.uni-heidelberg.de (T.E.); fabian.weykamp@med.uni-heidelberg.de (F.W.); \\ thomas.held@med.uni-heidelberg.de (T.H.); lisa-antonia.dinges@med.uni-heidelberg.de (L.-A.D.); \\ fabian.schunn@med.uni-heidelberg.de (F.S.); juergen.debus@med.uni-heidelberg.de (J.D.); \\ rami.elshafie@med.uni-heidelberg.de (R.A.E.S.); sebastian.adeberg@med.uni-heidelberg.de (S.A.) \\ 2 National Center for Radiation Oncology (NCRO), Heidelberg Institute for Radiation Oncology (HIRO), \\ Im Neuenheimer Feld 400, 69120 Heidelberg, Germany \\ 3 National Center for Tumor diseases (NCT), 69120 Heidelberg, Germany; \\ hauke.winter@med.uni-heidelberg.de (H.W.); michael.thomas@med.uni-heidelberg.de (M.T.) \\ 4 Department of Thoracic Surgery, Thoraxklinik at Heidelberg University Hospital, Roentgenstrasse 1, \\ 69126 Heidelberg, Germany \\ 5 Translational Lung Research Center Heidelberg (TLRC-H), Member of the German Center for Lung \\ Research (DZL), 69120 Heidelberg, Germany \\ 6 Department of Thoracic Oncology, Thoraxklinik at Heidelberg University Hospital, Roentgenstrasse 1, \\ 69126 Heidelberg, Germany \\ 7 Heidelberg Ion-Beam Therapy Center (HIT), Department of Radiation Oncology, \\ Heidelberg University Hospital, 69120 Heidelberg, Germany \\ 8 Clinical Cooperation Unit Radiation Oncology, German Cancer Research Center (DKFZ), \\ 69120 Heidelberg, Germany \\ * Correspondence: Juliane.Hoerner-Rieber@med.uni-heidelberg.de
}

Received: 10 August 2020; Accepted: 1 October 2020; Published: 5 October 2020

Simple Summary: Stereotactic body radiotherapy (SBRT) enables highly focused irradiation of lung tumors and has become a standard treatment. However, SBRT of lung tumors with close proximity to the central airways or mediastinum (central and ultracentral tumors) is associated with an increased risk for severe complications (bronchial bleeding, blockage of bronchi with loss of lung function). This retrospective study analyzed lung function and survival after risk-adapted approaches of SBRT in 107 central and ultracentral lung tumors. Lung function (vital capacity, forced expiratory volume in the first second) showed a statistically significant but in absolute numbers modest decrease that correlated moderately with the maximum radiation dose to the central airways. Stronger decrease in pulmonary function was found to be associated with limited survival. Consequently, lung function tests should be an integral element of follow-up after SBRT of lung tumors with proximity to the central airways or mediastinum.

Abstract: Stereotactic body radiotherapy (SBRT) to central and ultracentral lung tumors carries a risk of excessive toxicity. This study analyzed changes in pulmonary function tests (PFT) and their correlation with overall survival (OS) in 107 patients following central $(n=62)$ or ultracentral $(n=45)$ lung SBRT. Ultracentral location was defined as planning target volume overlap with the proximal 
bronchial tree (PBT). Vital capacity (VC) $(-0.31$, absolute $-9.4 \%$ of predicted, both $p<0.001)$ and forced expiratory volume in the first second $\left(\mathrm{FEV}_{1 \mathrm{~s}}\right)(-0.2 \mathrm{l}$, absolute $-7.7 \%$ of predicted, both $p<0.001)$ significantly decreased following SBRT. Higher maximum dose to the PBT significantly correlated with a steeper decline in VC $(p=0.005)$ and $\mathrm{FEV}_{1 \mathrm{~s}}(p=0.03)$ over time. Pronounced decline in $\mathrm{FEV}_{1 \mathrm{~s}}$ between 6 and 12 months ( $\mathrm{HR}=0.90, p=0.006)$ and pronounced decline in VC between baseline and 12 months ( $\mathrm{HR}=0.95, p=0.004)$ independently correlated with worse OS. Consequently, PFT presented a statistically significant albeit clinically mild decrease in lung volumes following central and ultracentral SBRT that correlated moderately with maximum dose to the PBT. Stronger decline in pulmonary function was associated with constrained survival, advocating consequent performance of PFT during follow-up.

Keywords: SBRT; non-small cell lung cancer; oligometastases; central; ultracentral; pulmonary function; lung volume; toxicity

\section{Introduction}

In the past few years, stereotactic body radiotherapy (SBRT) has advanced to a standard treatment in medically inoperable patients with early-stage non-small cell lung cancer (NSCLC) [1-3] as well as pulmonary oligometastases $[4,5]$. Nevertheless, SBRT of lung tumors in a central location, defined as a location less than $2 \mathrm{~cm}$ from the proximal bronchial tree (PBT) [6], remains a challenge. Application of sufficiently high doses to the tumor must be weighed against the risk for possibly severe toxicity [7-9]. In recent years, it has been demonstrated that the risk for excessive toxicity and even mortality increases with proximity to the PBT, so that ultracentral tumors in contact with the PBT are at especially high risk $[7,8,10]$. While more protracted SBRT fractionations have been successfully established for treatment of central tumors [2,6], there is still no strong evidence or consensus on treatment for ultracentral lesions [9]. Besides the increased incidence of bronchopulmonary bleeding [8,11], bronchial strictures and loss of lung volume are among the major concerns following central and ultracentral SBRT [7]. However, data on pulmonary function testing following central and especially ultracentral SBRT are scarce. Most analyses incorporate only peripheral tumors $[12,13]$ or a low number of central tumors [14,15]. Only one retrospective analysis directly compared toxicity due to decrease in PFT parameters between central and peripheral lung tumors [16]. Data on ultracentral lesions are lacking. The aim of this study is to investigate the time course of pulmonary function test (PFT) parameters following risk-adapted SBRT of central and ultracentral lung tumors.

\section{Results}

\subsection{Pulmonary Function Parameters}

The simple course of PFT parameters over time was evaluated descriptively as well as employing linear mixed models (LMM) with time as a fixed effect and a random intercept for each subject to deal with longitudinal data structure. The vital capacity $(\mathrm{VC})$ presented a statistically significant decline in absolute -0.31 ( $\beta=-0.21$ per 6 months, $p<0.001)$ and absolute $-9.4 \%$ of the predicted VC $(\beta=-5.1 \%$ per 6 months, $p<0.001$ ) within 12 months post-SBRT. Similarly, forced expiratory volume in the first second $\left(\mathrm{FEV}_{1 \mathrm{~s}}\right)$ significantly decreased by absolute $-0.21(\beta=-0.11$ per 6 months, $p<0.001)$ and by absolute $-7.7 \%$ of the predicted $\mathrm{FEV}_{1 \mathrm{~s}}(\beta=-4.4 \%$ per 6 months, $p<0.001$ ) within 12 months post-SBRT. The ratio $\mathrm{VC} / \mathrm{FEV}_{1 \mathrm{~s}}$ did not present a time trend in the descriptive analysis, which was confirmed by a statistically non-significant $\beta$-coefficient in the LMM ( $\beta=0.1 \%$ per 6 months, $p=0.89)$. Results of the simple time course analysis are summarized in Table 1 and illustrated in Figure 1. 
Table 1. Changes in different pulmonary function tests over time. Values are given as mean \pm standard deviation. Linear mixed model-based estimates for the $\beta$-coefficients of time as fixed effect are given with $95 \%$ confidence intervals $(\mathrm{CI})$ and corresponding p-values. VC: vital capacity, $\mathrm{FEV}_{1 \mathrm{~s}}$ : forced expiratory volume in 1 second, $\Delta$ : absolute difference.

\begin{tabular}{|c|c|c|c|}
\hline $\begin{array}{c}\text { Pulmonary_Function } \\
\text { Parameter }\end{array}$ & $\begin{array}{l}\text { Baseline } \\
(n=107)\end{array}$ & $\begin{array}{l}6 \text { Months } \\
(n=73)\end{array}$ & $\begin{array}{l}12 \text { Months } \\
\quad(n=55)\end{array}$ \\
\hline $\begin{array}{c}\mathrm{FEV}_{1 \mathrm{~s}}[1] \\
(\Delta \text { baseline })\end{array}$ & $\begin{array}{l}1.7 \pm 0.8 \\
\quad(0)\end{array}$ & $\begin{array}{c}1.5 \pm 0.6 \\
(-0.2 \pm 0.3)\end{array}$ & $\begin{array}{c}1.5 \pm 0.6 \\
(-0.2 \pm 0.3)\end{array}$ \\
\hline$\beta$ estimate $[1 / 6$ months $]$ & \multicolumn{3}{|c|}{$\beta=-0.1[-0.2--0.1], p=2 \times 10^{-9}$} \\
\hline $\begin{array}{c}\mathrm{FEV}_{1 \mathrm{~s}}[\% \text { predicted }] \\
(\Delta \text { baseline })\end{array}$ & $\begin{array}{c}69.5 \pm 26.5 \\
(0)\end{array}$ & $\begin{array}{c}61.9 \pm 21.1 \\
(-8.5 \pm 12.6)\end{array}$ & $\begin{array}{c}60.8 \pm 22.9 \\
(-7.7 \pm 12.4)\end{array}$ \\
\hline$\beta$ estimate $[\% / 6$ months $]$ & \multicolumn{3}{|c|}{$\beta=-4.4[-6.0--2.9], p=1 \times 10^{-8}$} \\
\hline $\begin{array}{c}\mathrm{VC}[1] \\
(\Delta \text { baseline })\end{array}$ & $\begin{array}{l}2.8 \pm 1.0 \\
\quad(0)\end{array}$ & $\begin{array}{c}2.6 \pm 1.0 \\
(-0.2 \pm 0.5)\end{array}$ & $\begin{array}{c}2.5 \pm 0.9 \\
(-0.3 \pm 0.5)\end{array}$ \\
\hline$\beta$ estimate $[1 / 6$ months $]$ & \multicolumn{3}{|c|}{$\beta=-0.2[-0.2--0.1], p=6 \times 10^{-8}$} \\
\hline $\begin{array}{c}\text { VC }[\% \text { predicted }] \\
\text { ( } \Delta \text { baseline })\end{array}$ & $\begin{array}{c}85.6 \pm 20.4 \\
(0)\end{array}$ & $\begin{array}{c}77.6 \pm 18.4 \\
(-7.8 \pm 14.9)\end{array}$ & $\begin{array}{c}76.3 \pm 19.9 \\
(-9.4 \pm 14.5)\end{array}$ \\
\hline$\beta$ estimate $[\% / 6$ months $]$ & \multicolumn{3}{|c|}{$\beta=-5.1[-6.9--3.3], p=2 \times 10^{-8}$} \\
\hline $\begin{array}{c}\mathrm{FEV}_{1 \mathrm{~s}} / \mathrm{VC}[\%] \\
(\Delta \text { baseline })\end{array}$ & $\begin{array}{l}61.5 \pm 16 \\
(0)\end{array}$ & $\begin{array}{l}61.3 \pm 16.0 \\
(-0.9 \pm 6.1)\end{array}$ & $\begin{array}{l}60.9 \pm 16.6 \\
(0.5 \pm 6.8)\end{array}$ \\
\hline$\beta$ estimate $[1 \% / 6$ months $]$ & \multicolumn{3}{|c|}{$\beta=0.1[-0.7-0.8], p=0.89$} \\
\hline
\end{tabular}
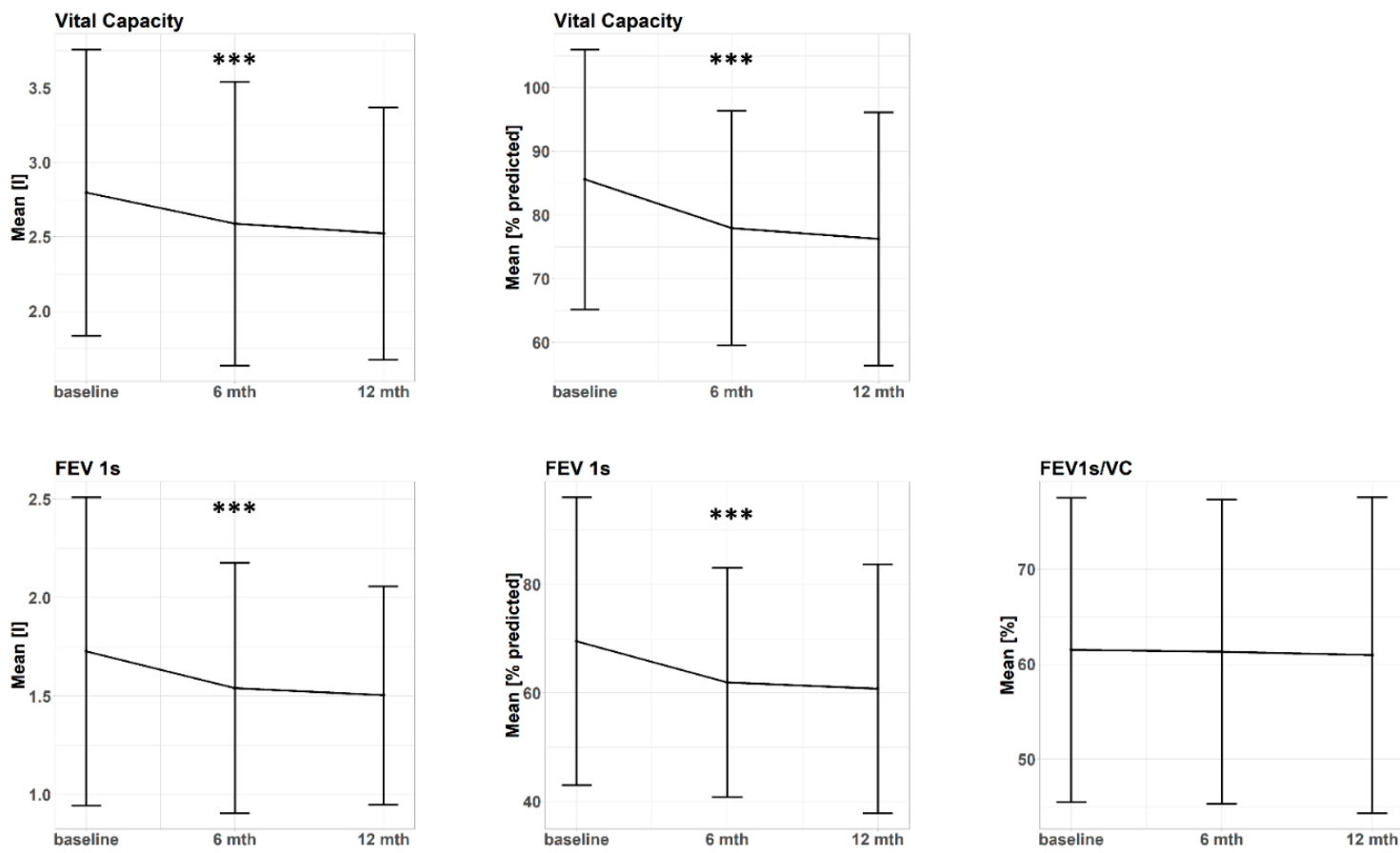

Figure 1. Progression of different pulmonary function parameters following central or ultracentral stereotactic body radiotherapy (SBRT). Data points represent mean values and error bars represent \pm 1 standard deviation. FEV 1s: forced expiratory volume in the first second, VC: vital capacity, l: liter, mth: months, ${ }^{* * *}: p<0.001$.

$\mathrm{VC}$ and $\mathrm{FEV}_{1 \mathrm{~s}}$ given as percentages of the predicted values were further assessed employing LMM with time, one additional clinical or dosimetry variable and the respective interaction term as fixed effects. Details of the LMM assessment are given in Table 2. 
Table 2. Linear mixed model analysis. All models include one random intercept per individual subject (random effect). Reference values for each fixed effect are included in brackets. Estimates for the $\beta$-coefficients of the fixed effects are given with $95 \%$ confidence intervals $(\mathrm{CI})$ and corresponding p-values. VC: vital capacity, $\mathrm{FEV}_{1 \mathrm{~s}}$ : forced expiratory volume in 1 second, CCI: Charlson Comorbidity Index, $\mathrm{ST}=$ systemic treatment, $\mathrm{BED} \alpha / \beta$ : biologically effective dose based on the $\alpha / \beta$ ratio, PBT: proximal bronchial tree, $\mathrm{PTV}=$ planning target volume, $\bullet$ : interaction term.

\begin{tabular}{|c|c|c|c|c|}
\hline \multirow{2}{*}{ Fixed Effects } & \multicolumn{2}{|c|}{ VC [\% Predicted] } & \multicolumn{2}{|c|}{ FEV $_{1 \mathrm{~s}}[\%$ Predicted $]$} \\
\hline & $\beta[95 \% \mathrm{CI}]$ & $p$-Value & $\beta[95 \% \mathrm{CI}]$ & $p$-Value \\
\hline Age (1 year) & $0[-0.4-0.4]$ & 0.98 & $0[-0.5-0.4]$ & 0.91 \\
\hline Time (6 months) & $-14.2[-26.4--1.9]$ & 0.02 & $-9.8[-23.4--2.4]$ & 0.02 \\
\hline Age Time & $0.1[0-0.3]$ & 0.14 & $0.1[0-0.3]$ & 0.11 \\
\hline CCI (1 point) & $-1.5[-3.6-0.6]$ & 0.15 & $-3.1[-5.7--0.6]$ & 0.02 \\
\hline Time (6 months) & $-4.9[-9.6-0.2]$ & 0.04 & $-5.7[-10.3--2.4]$ & $2 \times 10^{-3}$ \\
\hline CCI Time & $0[-1.1-1.0]$ & 0.93 & $0.2[-0.4-1.3]$ & 0.31 \\
\hline Localization (central) & $6.0[-1.4-13.5]$ & 0.11 & $7.5[-1.8-16.8]$ & 0.12 \\
\hline Time (6 months) & $-5.3[-7.6--3.0]$ & $6 \times 10^{-6}$ & $-4.5[-6.4--2.5]$ & $1 \times 10^{-5}$ \\
\hline Localization $\bullet$ Time & $0.6[-3.0-4.2]$ & 0.75 & $-1.1[-3.0-3.1]$ & 0.97 \\
\hline Following ST (none) & $-0.3[-10.4-9.8]$ & 0.95 & $6.3[-6.3-18.9]$ & 0.33 \\
\hline Time (6 months) & $-5.0[-7.1--2.8]$ & $5 \times 10^{-6}$ & $-4.0[-5.8--2.2]$ & $2 \times 10^{-5}$ \\
\hline Following ST Time & $-0.3[-5.0-4.5]$ & 0.91 & $-1.3[-5.6-2.5]$ & 0.45 \\
\hline Pneumonitis (none) & $3.8[-7.0-14.5]$ & 0.49 & $6.8[-17.8-15.8]$ & 0.32 \\
\hline Time (6 months) & $-5.1[-7.1--3.2]$ & $1 \times 10^{-7}$ & $-4.4[-6.1--2.9]$ & $1 \times 10^{-7}$ \\
\hline Pneumonitis Time & $0.4[-4.9-5.7]$ & 0.88 & $-0.2[-4.1-5.0]$ & 0.94 \\
\hline Local Progression (none) & $5.1[-8.3-18.6]$ & 0.46 & $-1.0[-20.5-15.8]$ & 0.91 \\
\hline Time (6 months) & $-5.1[-7.0--3.2]$ & $2 \times 10^{-7}$ & $-4.5[-6.6--3.1]$ & $7 \times 10^{-8}$ \\
\hline Local Progression Time & $-0.3[-5.6-5.0]$ & 0.88 & $0.4[-3.3-6.7]$ & 0.85 \\
\hline PBT Max (10 Gy) & $0.4[-0.4-1.2]$ & 0.33 & $0.1[-0.9-1.1]$ & 0.82 \\
\hline Time (6 months) & $2.6[-2.7-7.9]$ & 0.34 & $0.5[-4.2-5.2]$ & 0.82 \\
\hline PBT Max Time & $-0.6[-1.0--0.2]$ & $3 \times 10^{-3}$ & $-0.4[-0.7-0]$ & 0.03 \\
\hline Total Lung Mean (10 Gy) & $14.2[5.7-22.6]$ & $1 \times 10^{-3}$ & $21.0[10.6-31.4]$ & $8 \times 10^{-5}$ \\
\hline Time (6 months) & $-0.2[-5.0-4.7]$ & 0.95 & $-1.1[-5.2-3.0]$ & 0.61 \\
\hline Total Lung Mean Time & $-4.8[-9.2--0.4]$ & 0.03 & $-3.1[-6.8-0.6]$ & 0.10 \\
\hline PTV Size $\left(10 \mathrm{~cm}^{3}\right)$ & $0.6[0.1-1.0]$ & 0.01 & $0.6[0.1-1.2]$ & 0.03 \\
\hline Time (6 months) & $-3.5[-6.4--0.7]$ & 0.02 & $-3.6[-6.1--1.1]$ & $5 \times 10^{-3}$ \\
\hline PTV Time & $-0.1[-0.4-0.1]$ & 0.16 & $-0.1[-0.3-0.1]$ & 0.31 \\
\hline Time (6 months) & $6.7[0.1-13.4]$ & 0.05 & $0.6[-4.1-5.3]$ & 0.80 \\
\hline CCI (1 point) & --- & --- & $-2.8[-5.3--0.4]$ & 0.02 \\
\hline $\begin{array}{c}\text { PBT Max Time } \\
(10 \text { Gy } \bullet 6 \text { months })\end{array}$ & $-0.5[-0.9--0.2]$ & $5 \times 10^{-3}$ & $-0.4[-0.7-0]$ & 0.03 \\
\hline PTV Size $\left(10 \mathrm{~cm}^{3}\right)$ & $0.3[-0.2-0.8]$ & 0.18 & $0.2[-0.4-0.9]$ & 0.44 \\
\hline Total Lung Mean (10 Gy) & $10.3[0.4-20.1]$ & 0.04 & $13.6[2.0-5.2]$ & 0.02 \\
\hline $\begin{array}{c}\text { Total Lung Mean Time } \\
(10 \text { Gy } 6 \text { months })\end{array}$ & $-4.6[-8.9--0.2]$ & 0.04 & --- & --- \\
\hline
\end{tabular}

The VC showed a statistically significant positive correlation with the mean biologically effective dose (with an assumed $\alpha / \beta$ ratio $=3, \mathrm{BED}_{3}$ ) in both lungs ( $\beta=14.2 \%$ per $10 \mathrm{~Gy}$ ) and a positive correlation with planning target volume (PTV) size $\left(\beta=0.6 \%\right.$ per $\left.10 \mathrm{~cm}^{3}\right)$. Moreover, the maximum $\mathrm{BED}_{3}$ to the PBT ( $\beta=-0.6$ per 6 months and $10 \mathrm{~Gy}$ ) and the mean $\mathrm{BED}_{3}$ in both lungs ( $\beta=-4.8 \%$ per 6 months and $10 \mathrm{~Gy}$ ) yielded statistically significant negative interactions with time. Assessment of all significant variables in a joint LMM showed time ( $\beta=6.7 \%$ per 6 months), mean $\mathrm{BED}_{3}$ in both lungs ( $\beta=10.3 \%$ per $10 \mathrm{~Gy})$, the interaction between time and the maximum $\mathrm{BED}_{3}$ to the PBT ( $\beta=-0.5 \%$ per 
6 months and $10 \mathrm{~Gy})$ and the interaction between time and the mean $\mathrm{BED}_{3}$ in both lungs $(\beta=-4.6 \%$ per 6 months and $10 \mathrm{~Gy}$ ) as statistically significant predictors of the VC.

The $\mathrm{FEV}_{1 \mathrm{~s}}$ significantly correlated with the mean $\mathrm{BED}_{3}$ in both lungs ( $\beta=21.0 \%$ per $\left.10 \mathrm{~Gy}\right)$, PTV size ( $\beta=0.6 \%$ per $\left.10 \mathrm{~cm}^{3}\right)$ and the Charlson Comorbidity Index (CCI) $(\beta=-3.1 \%$ per 1 point). A statistically significant interaction with time was shown for maximum $\mathrm{BED}_{3}$ to the $\mathrm{PBT}(\beta=-0.4 \%$ per 6 months and $10 \mathrm{~Gy})$. Joint analysis of all significant variables showed $\mathrm{CCI}(\beta=-2.8 \%$ per 1 point), mean $\mathrm{BED}_{3}$ in both lungs ( $\beta=13.6$ per $10 \mathrm{~Gy}$ ) and the interaction between time and maximum $\mathrm{BED}_{3}$ to the PBT ( $\beta=-0.4$ per 6 months and $10 \mathrm{~Gy}$ ) as statistically significant predictors of the $\mathrm{FEV}_{1 \mathrm{~s}}$.

Figures 2 and 3 illustrate the course of $\mathrm{VC}$ and $\mathrm{FEV}_{1 \mathrm{~s}}$ over time for selected patient subgroups. Figures S1 and S2 present further patient subgroups. Figure S3 yields the course of $\mathrm{FEV}_{1 \mathrm{~s}} / \mathrm{VC}$ for different subgroups over time, which were only analyzed descriptively.
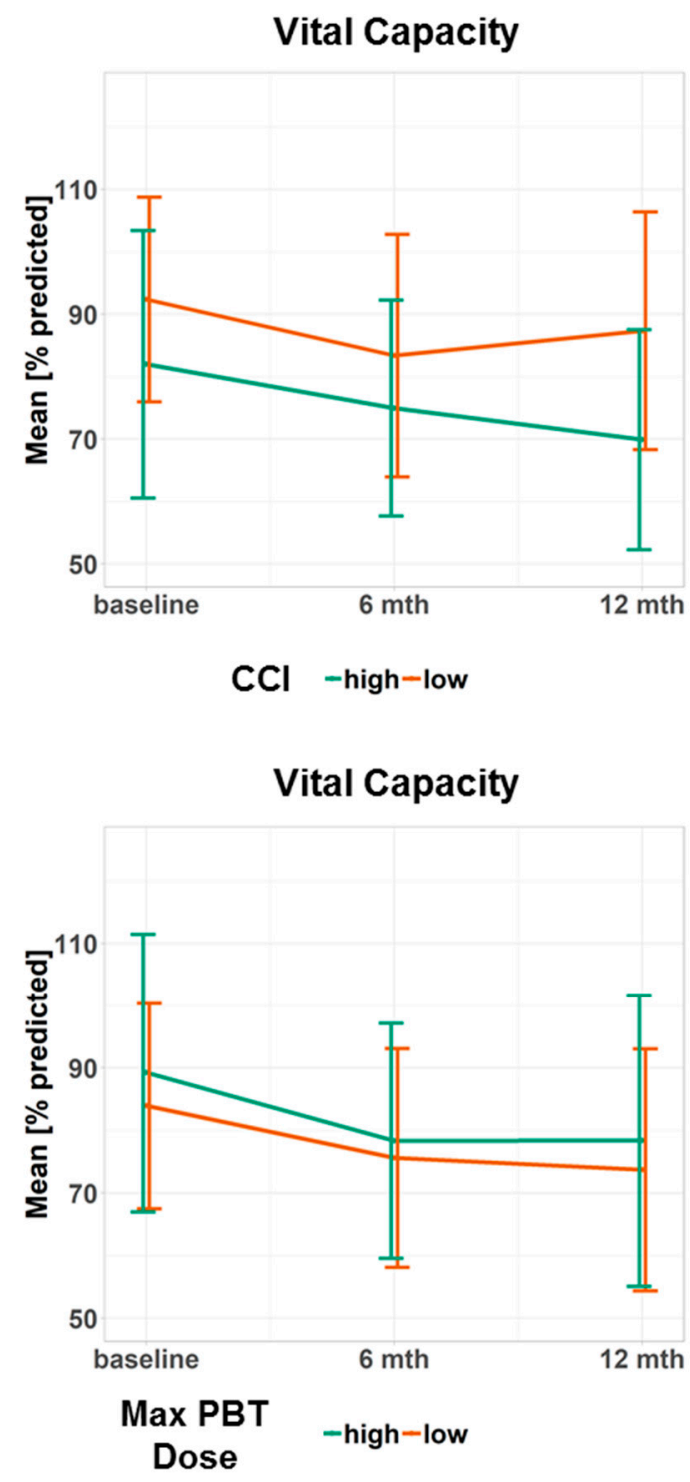

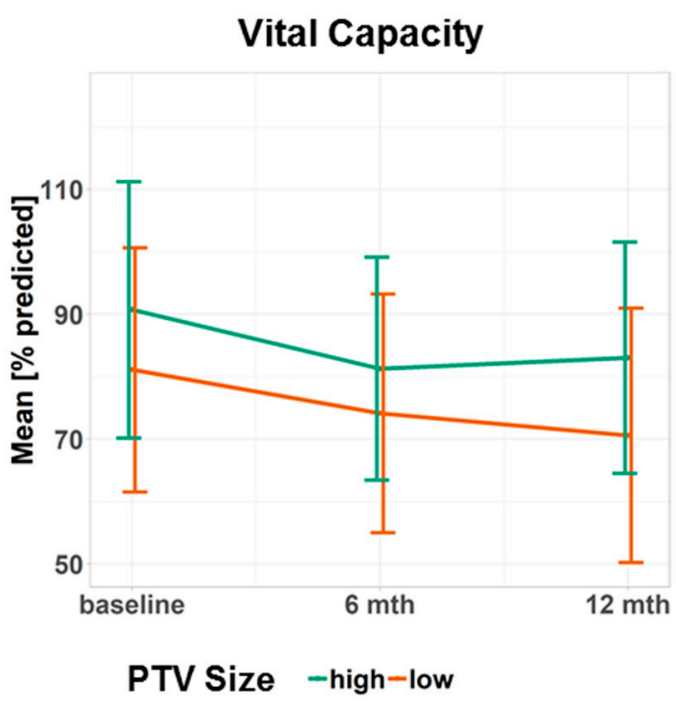

Vital Capacity

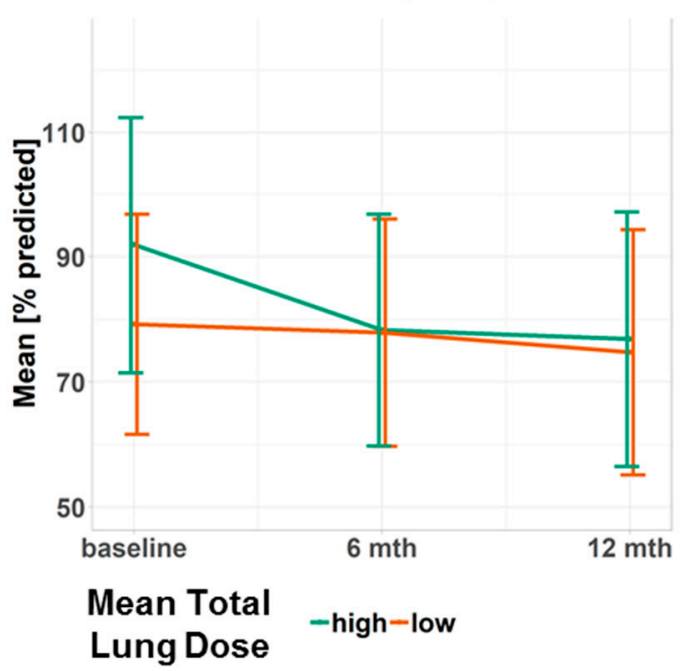

Figure 2. Progression of the vital capacity for different subgroups. Data points represent the mean value at a given time point. Error bars visualize \pm 1 standard deviation. The continuous predictor variables were dichotomized at the median to obtain two groups, one with high and one with low values of the variable. Doses refer to the biologically effective dose based on an $\alpha / \beta$ ratio $=3$. CCI: Charlson Comorbidity Index, PTV: planning target volume, PBT: proximal bronchial tree, max: maximum. 
FEV 1s

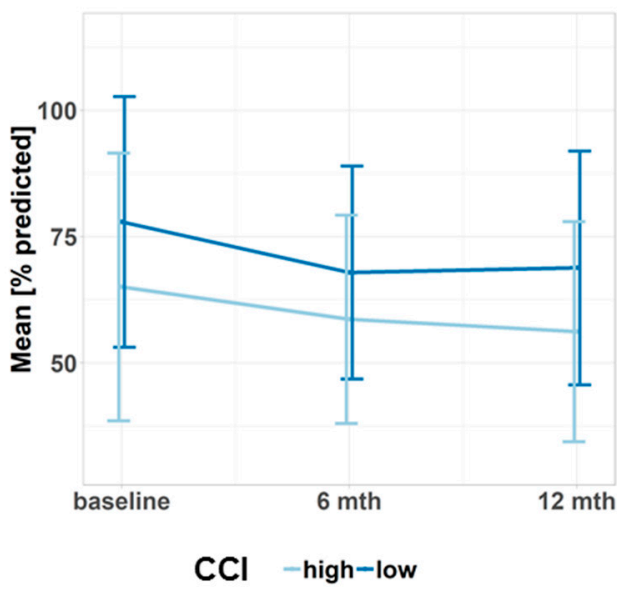

FEV 1s

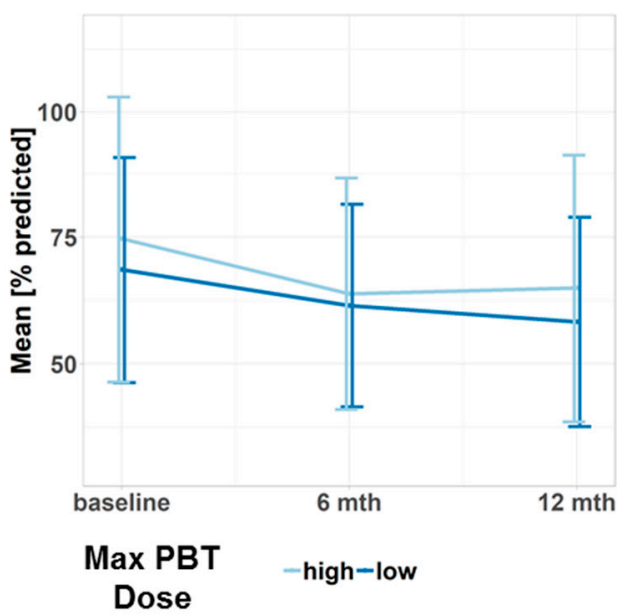

FEV 1s

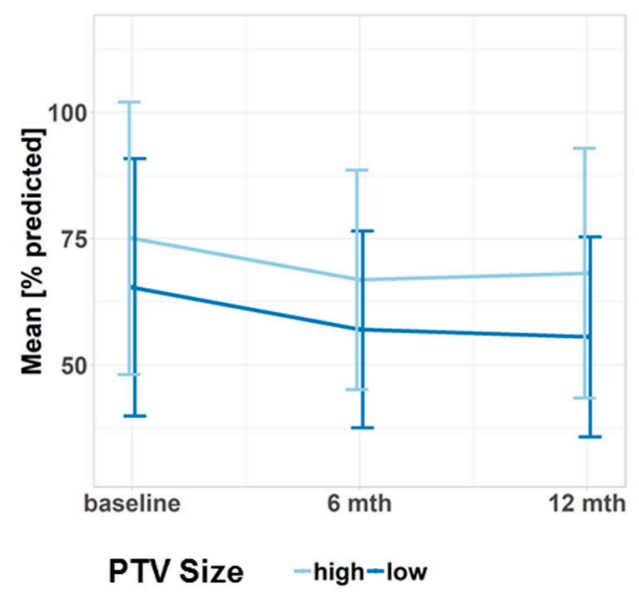

FEV 1s

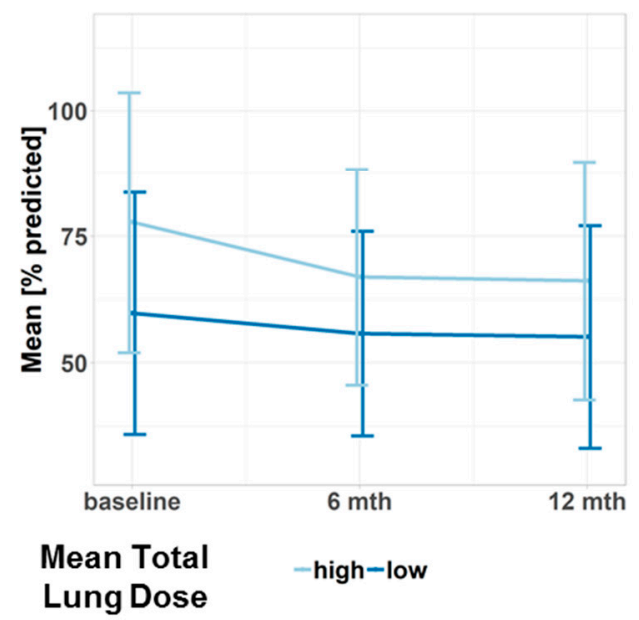

Figure 3. Progression of the forced expiratory volume in the first second (FEV 1s) for different subgroups. Data points represent the mean value at a given time point. Error bars visualize \pm 1 standard deviation. The continuous predictor variables were dichotomized at the median to obtain two groups, one with high and one with low values of the variable. Doses refer to the biologically effective dose based on an $\alpha / \beta$ ratio $=3$. CCI: Charlson Comorbidity Index, PTV: planning target volume, PBT: proximal bronchial tree, max: maximum.

\subsection{Overall Survival}

Univariate regression yielded decreased baseline $\mathrm{FEV}_{1 \mathrm{~s}} / \mathrm{VC}$ ratio (hazard ratio $(\mathrm{HR})=0.98$ ), decreased baseline $F E V_{1 \mathrm{~s}}$ as percentage of predicted $\mathrm{FEV}_{1 \mathrm{~s}}(\mathrm{HR}=0.99)$, stronger decline in $\mathrm{FEV}_{1 \mathrm{~s}}$ between 6 and 12 months $\left(\mathrm{FEV}_{1 \mathrm{~s}}\right.$ as percent of predicted: $\mathrm{HR}=0.91$, absolute $\mathrm{FEV}_{1 \mathrm{~s}}$ in liter: $\left.\mathrm{HR}=0.02\right)$, stronger decline in $\mathrm{VC}$ between baseline and 12 months (VC as percent of predicted: $\mathrm{HR}=0.97$, absolute VC in liter: $\mathrm{HR}=0.35$ ) as well as stronger decline in VC between 6 and 12 months (VC as percent of predicted: $\mathrm{HR}=0.95$, absolute $\mathrm{FEV}_{1 \mathrm{~s}}$ in liter: $\mathrm{HR}=0.30$ ) as statistically significant predictors of worse OS. Multivariate regression showed an independent association of stronger decline in $\mathrm{FEV}_{1 \mathrm{~s}}$ between 6 and 12 months $\left(\mathrm{FEV}_{1 \mathrm{~s}}\right.$ as percent of predicted: $\left.\mathrm{HR}=0.90\right)$ and stronger decline in VC between baseline and 12 months (VC as percent of predicted: $\mathrm{HR}=0.95$ ) with poor OS. Table 3 summarizes all results from Cox regression analysis. 
Table 3. Analysis of overall survival. Correlation of overall survival with different parameters of pulmonary function tests over time. Regression analysis was based on Cox proportional hazard models. HR: hazard ratio, $\mathrm{CI}$ : confidence interval, $\mathrm{FEV}_{1 \mathrm{~s}}$ : forced expiratory volume in 1 second, VC: vital capacity, pred: predicted value, $\Delta$ : absolute difference, $B E D \alpha / \beta$ : biologically effective dose based on the $\alpha / \beta$ ratio, PBT: proximal bronchial tree.

\begin{tabular}{|c|c|c|}
\hline \multicolumn{3}{|c|}{ Univariate } \\
\hline Pulmonary Function Parameter & HR $(95 \%$ CI $)$ & $p$-Value \\
\hline $\mathrm{FEV}_{1 \mathrm{~s}}[1]$ & $0.93(0.64-1.37)$ & 0.73 \\
\hline $\mathrm{FEV}_{1 \mathrm{~s}}[\%$ pred $]$ & $0.99(0.98-1.0)$ & 0.03 \\
\hline $\mathrm{VC}[1]$ & $1.22(0.92-1.62)$ & 0.18 \\
\hline VC [\% pred] & $0.99(0.98-1.01)$ & 0.34 \\
\hline $\mathrm{FEV}_{1 \mathrm{~s}} / \mathrm{VC}[\%]$ & $0.98(0.96-1.0)$ & 0.01 \\
\hline$\Delta \mathrm{FEV}_{1 \mathrm{~s}}(0-6$ months $)[1]$ & $1.25(0.39-3.97)$ & 0.71 \\
\hline$\Delta \mathrm{FEV}_{1 \mathrm{~s}}(0-6$ months) [\% pred] & $1.02(0.99-1.04)$ & 0.29 \\
\hline$\Delta \mathrm{FEV}_{1 \mathrm{~s}}(0-12$ months $)[1]$ & $0.40(0.13-1.26)$ & 0.12 \\
\hline$\Delta \mathrm{FEV}_{1 \mathrm{~s}}(0-12$ months $)[\%$ pred] & $0.99(0.96-1.01)$ & 0.30 \\
\hline$\Delta \mathrm{FEV}_{1 \mathrm{~s}}(6-12$ months) [1] & $0.02(0-0.21)$ & $1 \times 10^{-3}$ \\
\hline$\Delta \mathrm{FEV}_{1 \mathrm{~s}}(6-12$ months) [\% pred] & $0.91(0.86-0.97)$ & $4 \times 10^{-3}$ \\
\hline$\Delta \mathrm{VC}(0-6$ months $)[1]$ & $0.951(0.48-1.87)$ & 0.88 \\
\hline$\Delta \mathrm{VC}$ (0-6 months) [\% pred] & $1.0(0.98-1.02)$ & 0.81 \\
\hline$\Delta \mathrm{VC}(0-12$ months $)[1]$ & $0.35(0.17-0.74)$ & $6 \times 10^{-3}$ \\
\hline$\Delta \mathrm{VC}(0-12$ months $)[\%$ pred] & $0.97(0.95-1.0)$ & 0.03 \\
\hline$\Delta \mathrm{VC}(6-12$ months $)[1]$ & $0.30(0.15-0.63)$ & $1 \times 10^{-3}$ \\
\hline$\Delta \mathrm{VC}(6-12$ months $)[\%$ pred] & $0.95(0.92-0.98)$ & $1 \times 10^{-3}$ \\
\hline$\Delta \mathrm{FEV}_{1 \mathrm{~s}} / \mathrm{VC}(0-6$ months $)[\%]$ & $1.03(0.98-1.09)$ & 0.19 \\
\hline$\Delta \mathrm{FEV}_{1 \mathrm{~s}} / \mathrm{VC}(0-12$ months $)[\%]$ & $1.02(0.97-1.07)$ & 0.42 \\
\hline$\Delta \mathrm{FEV}_{1 \mathrm{~s}} / \mathrm{VC}(6-12$ months) [\%] & $1.0(0.95-1.06)$ & 0.93 \\
\hline \multicolumn{3}{|l|}{ Multivariate } \\
\hline $\mathrm{FEV}_{1 \mathrm{~s}} / \mathrm{VC}[\%]$ & $1.0(0.95-1.05)$ & 0.86 \\
\hline $\mathrm{FEV}_{1 \mathrm{~s}}[\%$ pred $]$ & $0.97(0.94-1.0)$ & 0.09 \\
\hline$\Delta \mathrm{FEV}_{1 \mathrm{~s}}(6-12$ months) [\% pred] & $0.90(0.84-0.97)$ & $6 \times 10^{-3}$ \\
\hline$\Delta \mathrm{VC}(0-12$ months $)[\%$ pred] & $0.95(0.91-0.98)$ & $4 \times 10^{-3}$ \\
\hline$\Delta \mathrm{VC}(6-12$ months $)[\%$ pred] & $1.0(0.95-1.05)$ & 0.94 \\
\hline
\end{tabular}

\section{Discussion}

To our knowledge, we analyzed the largest dataset of PFT following central and ultracentral lung SBRT as dedicated subgroups so far. Both VC and FEV 1s $_{\mathrm{s}}$ significantly declined following SBRT, with a mean reduction of absolute $-9.4 \%$ in $\mathrm{VC}$ and absolute $-7.7 \%$ in $\mathrm{FEV}_{1 \mathrm{~s}}$ expressed as percentage of the predicted value. Given baseline values of $85.6 \%$ for $\mathrm{VC}$ and $69.5 \%$ for $\mathrm{FEV}_{1 \mathrm{~s}}$, this corresponds to an average relative decline of slightly more than $10 \%$. Hence, the average decline reaches a PFT-related toxicity grade I according to the RTOG 0813 scale $[6,16]$. Accordingly, SBRT is confirmed as a safe treatment for central and ultracentral lung tumors considering changes in pulmonary function. However, we found a significant correlation of dynamic PFT changes with OS. Therefore, some patients might be at higher risk due to more pronounced PFT changes. This advocates for the regular use of PFT during follow-up after central and ultracentral SBRT to detect vulnerable patients early. Even though the linear models suggest a continuous decline, descriptive analysis reveals that the decline in PFT is most pronounced during the first 6 months post-SBRT, with smaller changes towards the 12-month follow-up. This suggests the time points we investigated as very reasonable candidates for follow-up studies.

\subsection{Central vs. Peripheral SBRT}

In general, several previous studies of PFT following SBRT could not find significant changes in $\mathrm{FEV}_{1 \mathrm{~s}}$ and/or VC $[13,15,17,18]$. Conversely, Stanic et al. found a significant relative $-5.8 \%$ change in 
$\mathrm{FEV}_{1 \mathrm{~s}}$ two years after peripheral SBRT [19]. Accordingly, Stone et al. reported a relative drop in VC of around $4.6 \% 12$ months after SBRT in one of the largest cohorts of peripheral lung tumors reported so far [12]. These numbers suggest a smaller decline than the one we observed. Hörner-Rieber et al. showed a significant decline in $\mathrm{FEV}_{1 \mathrm{~s}}$ by absolute $5.2 \%$ at a median of 9 months after SBRT, including a small number of central tumors $(n=12 / 70)$ [14]. Guckenberger et al. investigated PFT values following SBRT in a patient cohort potentially including central tumors, finding a significant relative $-8.1 \%$ change in $\mathrm{FEV}_{1 \mathrm{~s}}$ between 7 and 24 months [20]. Both studies agree well with our findings, which also suggest that tumor location might have an impact on PFT changes following SBRT. While we could not find a significant correlation of ultracentral versus central tumor location with PFT changes, there was a significant interaction between decline in PFT and the maximum dose delivered to the PBT. Consequently, higher radiation doses to the PBT could indeed have an adverse impact on pulmonary function after SBRT. In this context, Stephans et al. compared a small subgroup of central tumors $(n=10)$ with peripheral tumors without finding significant PFT changes after SBRT in either group [15]. Furthermore, Mangona compared toxicity after peripheral and central SBRT in a larger collective, showing similar $\geq \mathrm{II}^{\circ}$ PFT toxicity rates of around $35 \%$ after 2 years for both groups [16]. Notably, such toxicity rates also suggest significant changes in PFT after SBRT in general. All in all, analyses of sufficiently large patient cohorts show that SBRT induces statistically significant but clinically moderate decreases in pulmonary function. Despite a potentially pronounced decline following higher radiation doses to the PBT, our data do not raise concerns about excessive toxicity due to loss of lung volume following risk-adapted central or ultracentral SBRT. The decline in $\mathrm{FEV}_{1 \mathrm{~s}}$ of absolute -0.21 or relative $-11.8 \%$ still compares favorably to PFT changes following surgical resection. A decline in $\mathrm{FEV}_{1 \mathrm{~s}}$ of -0.41 or relative $-17.6 \%$ depending on the extent of the resection was reported in a prior study comparing PFT after pulmonary surgery and SBRT [21]. Moreover, patients undergoing surgery are generally younger and present with less comorbidity [21].

\subsection{Clinical and Dosimetry Correlation}

SBRT is a standard treatment for patients with early-stage lung cancer unfit to undergo surgical resection or for patients with pulmonary oligometastases. Hence, interpretation of PFT changes over time following SBRT might be biased due to advanced age, severe comorbidities, tumor progression or consecutive systemic treatments. Consequently, we expanded our LMM to encompass factors other than SBRT which are possibly associated with a decline in PFT over time. The CCI showed a negative correlation with the $\mathrm{FEV}_{1 \mathrm{~s}}$ in the final linear model, whereas patient age, local tumor progression, application of consecutive systemic treatments or incidence of pneumonitis did not show such a correlation in any of the employed models. The correlation of $C C I$ with $\mathrm{FEV}_{1 \mathrm{~s}}$ suggests that $\mathrm{FEV}_{1 \mathrm{~s}}$ is generally lower in patients with higher burden of comorbidities. However, the interaction term between CCI and time did not show a significant effect. This establishes SBRT as an important reason for pulmonary function changes during the follow-up period, which is further supported by the stronger decline in PFT during the first 6 months after SBRT, as was visible in the descriptive analysis.

Due to the application of an internal target volume (ITV) concept for motion management, the mean PTV size of $105 \mathrm{~cm}^{3}$ was somewhat elevated compared to prior reports of lung SBRT [14,17], which might have contributed to a more pronounced decline in pulmonary function. Nevertheless, declines in pulmonary function remained modest.

Higher mean dose in both lungs was associated with significantly higher VC and $\mathrm{FEV}_{1 \mathrm{~s}}$ in general, which suggests that patients who received higher lung doses also started at higher baseline PFT values. Potentially, SBRT dose was chosen more aggressively to improve tumor control in patients with better pulmonary function. Prior studies showed a weak [15] or no correlation of PFT decrease with higher lung doses [14,20]. Accordingly, interaction terms between mean $\mathrm{BED}_{3}$ in both lungs and time after SBRT showed a statistically significant but clinically moderate correlation with VC. In particular, an additional $10 \mathrm{~Gy}$ mean $\mathrm{BED}_{3}$ to both lungs (corresponding to an excess of two standard deviations in our patient cohort) theoretically translated to a further decline in VC of absolute $-4.6 \%$ per 6 months. 
Furthermore, LMM suggested that increased maximum $\mathrm{BED}_{3}$ to the PBT was associated with a significantly pronounced decline in PFT. However, clinical effect size was limited, with incremental changes of absolute $-0.5 \%$ and $-0.4 \%$ per $10 \mathrm{~Gy} \mathrm{BED}_{3}$ and 6 months for $\mathrm{VC}$ and $\mathrm{FEV}_{1 \mathrm{~s}}$, respectively.

Even though advanced patient age, a high burden of comorbidities and tumor progression surely contributed to the observed decrease in PFT parameters over time, our results suggest SBRT as one major reason for PFT decline. Despite being weak to moderate, correlations with mean lung dose as well as with maximum dose to the PBT support a risk-adapted approach to fractionation and dosing in central and ultracentral SBRT.

\subsection{Overall Survival}

Pre-treatment pulmonary function did not yield independent predictors of OS on multivariate analysis. While one prior study failed to show a correlation of pre-treatment PFT with overall survival [19], many authors found a correlation of more favorable pre-SBRT PFT with decreased survival $[12,15,17]$. This counterintuitive finding could be explained by severe cardiovascular disease as the main reason for medical inoperability in patients with good PFT in the corresponding studies, subsequently leading to higher cardiovascular mortality $[12,15,17]$. We found a stronger decline in VC between baseline and 12 months post-SBRT as well as a stronger decline in FEV ss $_{\text {s }}$ between 6 months and 12 months post-SBRT to be independent predictors of poor OS. A previous analysis of the association between post-treatment PFT parameters and OS could not show a correlation of poor PFT parameters with poor OS [12]. However, we did not analyze singular post-treatment PFT values, but the dynamic changes in PFT compared to baseline pulmonary function. Similarly, a previous analysis from our department including mainly peripheral tumors showed that the actual decline in the VC was an independent predictor of worse OS [14]. The progression of predicted $\mathrm{FEV}_{1 \mathrm{~s}}$ between 6 and 12 months had the highest impact on OS, yielding a hazard ratio of 0.90 per $1 \%$ absolute increase or 1.11 per $1 \%$ absolute decrease. This is intriguing because $\mathrm{FEV}_{1 \mathrm{~s}}$ seems to reach a plateau between 6and 12-months post-treatment in descriptive analysis. Obviously, a further decline in $\mathrm{FEV}_{1 \mathrm{~s}}$ in this timeframe confers an increased risk of mortality. Considering our results from correlation of PFT with clinical parameters, neither higher age nor higher burden of comorbidities significantly interacted with the PFT decrease following SBRT. Therefore, some patients might develop a stronger decrease in PFT independently of age and previous comorbidities. Consequently, our results advocate for the inclusion of PFT in regular follow-up visits after central or ultracentral lung SBRT. This might enable early detection of pronounced PFT changes as a predictor of worse outcome.

\subsection{Limitations and Strenghts}

Strengths of this study include conduction of all PFT at the same center. Furthermore, we report the largest cohort of patients with central and especially ultracentral tumors followed up with PFT after SBRT so far. All patients received standardized risk-adapted SBRT fractionations depending on tumor location. Besides this, our analysis suffers from several general limitations due to its retrospective nature. Firstly, investigation of a heterogeneous patient cohort that includes mostly elderly and frail patients or patients with advanced tumor disease limits interpretation of PFT changes over time. To adjust for some important confounders, we elaborated various LMM with patient age, comorbidity status and following systemic therapies as additional covariates. Other possible confounders such as smoking status, pulmonary comorbidities in specific as well as out-field tumor progression were not included in our analysis. Follow-up data on PFT were not available for all patients, which might have confounded our results. Moreover, PFT were performed at time points slightly varying from the ideal baseline, 6- and 12-months post-treatment. Additionally, spirometry relies on the patient's effort to cooperate during the examination, which could have distorted the longitudinal measurements. 


\section{Materials and Methods}

\subsection{Patients}

This retrospective analysis included 129 patients who consecutively received SBRT of central or ultracentral lung tumors at Heidelberg University Hospital between 2012 and 2019. Of these, 22 patients were excluded due to missing pre-treatment (baseline) PFT, so that a total of 107 patients were eligible for analysis. Central location was defined according to the RTOG 0813 trial [6] and ultracentral location was defined as an overlap of the PTV with the PBT [10]. Two patients received SBRT to two central lung lesions at the same time and only the bigger PTV was included in statistical modeling. All available data on pre-treatment comorbidities were used to retrospectively assign a CCI to each patient. The clinical outcomes as well as dosimetry parameters of this patient cohort are currently submitted for publication. Patient characteristics are shown in Table 4.

Table 4. Patients $(n=107)$. SD: standard deviation, CCI: Charlson Comorbidity Index, IQR: interquartile range, NSCLC: non-small cell lung carcinoma, PET: positron emission tomography, SBRT: stereotactic body radiotherapy, $\mathrm{BED} \alpha / \beta$ : biologically effective dose based on the $\alpha / \beta$ ratio, PBT: proximal bronchial tree, PTV: planning target volume, PFT: pulmonary function test, $\Delta$ : difference.

\begin{tabular}{|c|c|}
\hline \multicolumn{2}{|l|}{ Patient Characteristics } \\
\hline \multicolumn{2}{|l|}{ Age (years) } \\
\hline Mean \pm SD & $71.6 \pm 10.4$ \\
\hline \multicolumn{2}{|l|}{ Sex } \\
\hline Male & 52 \\
\hline Female & 55 \\
\hline \multicolumn{2}{|l|}{$\mathrm{CCI}$} \\
\hline Median (IQR) & $4(3-5)$ \\
\hline \multicolumn{2}{|l|}{ Localization } \\
\hline Central & 62 \\
\hline Ultracentral & 45 \\
\hline \multicolumn{2}{|l|}{ Tumor Entity } \\
\hline NSCLC & 88 \\
\hline PET Positive Lung Nodule* & 12 \\
\hline Extrapulmonary Primary & 7 \\
\hline \multicolumn{2}{|l|}{ SBRT Target } \\
\hline Primary & 68 \\
\hline Local Recurrence & 20 \\
\hline Lung Metastasis & 19 \\
\hline \multicolumn{2}{|c|}{ Systemic Therapy during Follow-Up } \\
\hline Chemotherapy & 8 \\
\hline Checkpoint Inhibition & 6 \\
\hline Chemotherapy + Checkpoint Inhibition & 1 \\
\hline Other & 4 \\
\hline None & 74 \\
\hline Unknown & 14 \\
\hline \multicolumn{2}{|l|}{ Maximum $\mathrm{BED}_{3}$ in PBT } \\
\hline Mean \pm SD & $115.7 \pm 49.2$ \\
\hline \multicolumn{2}{|l|}{ Mean $\mathrm{BED}_{3}$ in Total Lung } \\
\hline Mean \pm SD & $10.1 \pm 4.4$ \\
\hline \multicolumn{2}{|l|}{ PTV Size $\left(\mathrm{cm}^{3}\right)$} \\
\hline Mean \pm SD & $105.0 \pm 84.0$ \\
\hline \multicolumn{2}{|l|}{ PFT Time Intervals (days) } \\
\hline$\Delta$ Baseline-SBRT Start $($ Mean \pm SD) & $-42 \pm 30$ \\
\hline$\Delta$ SBRT Start-1st Follow-Up (Mean \pm SD) & $182 \pm 37$ \\
\hline$\Delta$ SBRT Start-2nd Follow-Up (Mean \pm SD) & $359 \pm 45$ \\
\hline \multicolumn{2}{|l|}{ Pneumonitis during Follow-Up } \\
\hline $\mathrm{II}^{\circ}$ & 10 \\
\hline $\mathrm{III}^{\circ}$ & 5 \\
\hline Local Progression during Follow-Up & 9 \\
\hline
\end{tabular}

* Cases where histological proof was not possible and lung lesion showed $\left({ }^{18} \mathrm{~F}\right)$-fluorodeoxyglucose (FDG) utilization on positron emission tomography typical for bronchial carcinoma. 


\subsection{Radiation Treatment}

Planning of SBRT employed a 4-dimensional (4D) CT imaging set. Patient immobilization relied on individually shaped body casts. To mitigate tumor motion, an abdominal compression device was employed if the tumor was in a lower lung lobe. Contouring of gross tumor volumes (GTVs) on several maximum extension phase images (encompassing maximum inspiration and expiration, middle breathing position) was performed to create an ITV. Clinical target volumes (CTV) were obtained by adding a 2-5 $\mathrm{mm}$ margin to the ITV. PTVs were obtained by adding another $3 \mathrm{~mm}$ margin to the CTV. Normal tissue constraints were in line with the UK consensus guidelines [22], with heart, lungs, PBT, esophagus, chest wall and spinal cord being regularly delineated as organs at risk (OAR). Due to central and ultracentral tumor location, risk-adapted SBRT fractionations were employed. Patients with central lung tumors were treated to a total dose of $60 \mathrm{~Gy}$ in 8 fractions prescribed to the encompassing $80 \%$ isodose [2]. Ultracentral lung tumors were treated to a total dose of 50 Gy in 10 fractions prescribed to the encompassing $95 \%$ isodose. OAR constraints were given priority over target coverage. Delivery techniques were either 3D, volumetric-modulated arc therapy (VMAT) or helical tomotherapy. Simultaneous systemic therapy was not performed. To enable comparability between the two different SBRT fractionations, the doses to lungs and PBT were converted to the biologically effective dose assuming an $\alpha / \beta$ ration of $3\left(\mathrm{BED}_{3}\right)$ according to the well-known linear-quadratic model:

$$
\operatorname{BED}_{\alpha / \beta}=\mathrm{n} \times \mathrm{d}(1+\mathrm{d} /(\alpha / \beta))
$$

\subsection{Follow-Up}

Patients were followed up every 3-6 months after SBRT, including clinical evaluation, plain radiography or computed tomography (CT) of the thorax and PFT at our institution. Most PFT data were available around 6 months and around 12 months post-SBRT. Regularly, PFT was based on spirometry and entailed $\mathrm{VC}, \mathrm{FEV}_{1 \mathrm{~s}}$ as well as the ratio of $\mathrm{FEV}_{1 \mathrm{~s}} / \mathrm{VC}$ (Tiffeneau index). VC and $\mathrm{FEV}_{1 \mathrm{~s}}$ were available as absolute values in liter (l). Moreover, corresponding expected lung volumes were predicted based on patient age, sex and body height according to the global lung function 2012 equations [23], which enabled expression of the different PFT parameters as percent of the predicted value (\% predicted). Local progression was defined as increase in tumor size within the high dose volume according to RECIST 1.1 on thoracic CT scan $(n=9)$. Furthermore, several patients received additional positron emission tomography (PET) CT $(n=2)$ or biopsy $(n=4)$ to confirm local progression. Occurrence of pneumonitis grade $\geq \mathrm{II}^{\circ}$ was retrospectively registered based on clinical and imaging findings according to the common terminology criteria of adverse events (CTCAE) in version 5.0. Overall survival (OS) was calculated from the first day of SBRT to patient death.

\subsection{Statistics}

Patient as well as tumor characteristics were evaluated descriptively. Furthermore, the development of PFT over time was analyzed descriptively for the whole patient cohort as well as between different patient subgroups. For quantitative assessment of PFT changes over time, LMM were developed for each PFT parameter as target variable. Due to longitudinal data structure, the individual subject was included as random effect so that all models encompassed one random intercept per patient. Firstly, basic time models were built with follow-up time (discretized to baseline, 6 months, 12 months) as the only fixed effect, showing a significant correlation of $\mathrm{FEV}_{1 \mathrm{~s}}$ as well as VC with follow-up time. For further evaluation, only $\mathrm{FEV}_{1 \mathrm{~s}}$ and $\mathrm{VC}$ values given as percent of the predicted volumes were chosen to reduce bias by age and sex. One more fixed effect and its interaction term with time were added to the basic time models of $\mathrm{FEV}_{1 \mathrm{~s}}$ and $\mathrm{VC}$ to evaluate possible differences in time trend. Lastly, all fixed effects that proved at least borderline significant $(\mathrm{p} \leq 0.05)$ were incorporated into a final LMM for $\mathrm{FEV}_{1 \mathrm{~s}}$ and VC. Variances were estimated based on the restricted maximum likelihood (REML) method. Confidence intervals were computed as profile confidence intervals and $p$-values were derived from the z-statistics. Q-Q-plots of the residuals as well as random intercepts for all LMM 
can be found in Figures S4-S8, showing approximately normal distributions for all models. Potential correlation of OS with baseline PFT as well as PFT differences between baseline and the two follow-ups was investigated using univariate Cox proportional hazard models. All variables that were statistically significant in univariate analysis were incorporated into a multivariate model. If both absolute values (in l) as well as normalized values (expressed as percent of predicted) proved statistically significant, only the corresponding normalized value (percent of predicted) was chosen for the multivariate model to avoid intercorrelation between the predictor variables. Confidence intervals and $p$-values of all HR were derived from Wald statistics. Level of statistical significance was set to $\alpha<0.05$. Since this was an exploratory analysis, $p$-values were calculated without adjusting for multiple comparisons and should be regarded as descriptive in nature. Statistical analysis was conducted with $\mathrm{R}$ in version 3.6.0 using the "rspiro" and "lme4" package.

\subsection{Ethics}

This retrospective trial received approval by the local ethics board (IRB number: S226/2020) and was conducted in accordance with the Declaration of Helsinki. Individual patient data will not be made publicly available according to national legislation and study ethics approval terms.

\section{Conclusions}

In general, SBRT of central and ultracentral lung tumors led to statistically significant albeit clinically mild changes in pulmonary function that were correlated moderately with the mean lung dose and maximum dose to the proximal bronchial tree. Hence, risk-adapted central and ultracentral SBRT is supported as a safe treatment modality. A stronger decline in pulmonary function was associated with constrained survival, which advocates for regular PFT follow-up in the first year after SBRT.

Supplementary Materials: The following are available online at http://www.mdpi.com/2072-6694/12/10/2862/ s1, Figure S1: Progression of vital capacity for further patient subgroups, Figure S2: Progression of forced expiratory volume in the first second (FEV 1s) for further patient subgroups, Figure S3: Progression of the forced expiratory volume in the first second to vital capacity ratio (FEV1s/VC) for different subgroups, Figure S4: Quantile-Quantile-Plot of Residuals for Linear Mixed Models for Vital Capacity Analysis, Figure S5: QuantileQuantile-Plot of Random Intercepts for Linear Mixed Models for Vital Capacity Analysis, Figure S6: QuantileQuantile-Plot of Residuals for Linear Mixed Models for Forced Expiratory Volume in the First Second Analysis, Figure S7: Quantile-Quantile-Plot of Random Intercepts for Linear Mixed Models for Forced Expiratory Volume in the First Second Analysis, Figure S8: Quantile-Quantile-Plot of Residuals and Random Intercepts for Simple Time Models.

Author Contributions: Conceptualization, S.R. and J.H.-R.; Data curation, S.R., T.E., F.W., T.H., L.-A.D., F.S., R.A.E.S. and S.A.; Formal analysis, S.R.; Methodology, S.R. and J.H.-R.; Supervision, H.W., M.T., J.D. and J.H.-R.; Writing—original draft, S.R. and J.H.-R.; Writing—review and editing, S.R., T.E., F.W., T.H., L.-A.D., F.S., H.W., M.T., J.D., R.A.E.S., S.A. and J.H.-R. All authors have read and agreed to the published version of the manuscript.

Funding: S.R. is funded by the Physician-Scientist Program of Heidelberg University, Faculty of Medicine. The sponsor was not involved in designing, conducting or presenting the analysis.

Acknowledgments: Special thanks go to Eric Tonndorf-Martini, Nina Bougatf, Matthias Ulrich and Andreas Kudak for excellent assistance in data pre-processing.

Conflicts of Interest: J.H.-R. received speaker fees and travel reimbursement from ViewRay Inc., as well as travel reimbursement form IntraOP Medical and Elekta Instrument AB outside the submitted work. T.E. received grants from Ruprecht-Karls Universität Heidelberg, Herbert Kienzle Foundation and Else Kröner-Fresenius Foundation and received travel reimbursement from Bristol-Myers Squibb outside the submitted work. S.A. and J.D. received grants from Accuray International Sàrl and Merck Serono GmbH outside the submitted work. J.D. received grants from CRI-The Clinical Research Institute GmbH, View Ray Inc., Accuray Incorporated, RaySearch Laboratories $\mathrm{AB}$, Vision RT limited, Astellas Pharma GmbH, Astra Zeneca GmbH, Solution Akademie GmbH, Ergomed PLC Surrey Research Park, Siemens Healthcare GmbH, Quintiles GmbH, Pharmaceutecal Research Associates $\mathrm{GmbH}$, Boehringer Ingelheim Pharma GmbH Co, PTW-Freiburg Pychlau GmbH and Nanobiotix A.A. outside the submitted work. 


\section{References}

1. Timmerman, R.; McGarry, R.; Yiannoutsos, C.; Papiez, L.; Tudor, K.; DeLuca, J.; Ewing, M.; Abdulrahman, R.; Desrosiers, C.; Williams, M.; et al. Excessive Toxicity When Treating Central Tumors in a Phase II Study of Stereotactic Body Radiation Therapy for Medically Inoperable Early-Stage Lung Cancer. J. Clin. Oncol. 2006, 24, 4833-4839. [CrossRef]

2. Lagerwaard, F.J.; Haasbeek, C.J.; Smit, E.F.; Slotman, B.J.; Senan, S. Outcomes of Risk-Adapted Fractionated Stereotactic Radiotherapy for Stage I Non-Small-Cell Lung Cancer. Int. J. Radiat. Oncol. 2008, 70, 685-692. [CrossRef]

3. Guckenberger, M.; Wulf, J.; Mueller, G.; Krieger, T.; Baier, K.; Gabor, M.; Richter, A.; Wilbert, J.; Flentje, M. Dose-Response Relationship for Image-Guided Stereotactic Body Radiotherapy of Pulmonary Tumors: Relevance of 4D Dose Calculation. Int. J. Radiat. Oncol. 2009, 74, 47-54. [CrossRef]

4. Hörner-Rieber, J.; Bernhardt, D.; Blanck, O.; Duma, M.; Eich, H.T.; Gerum, S.; Gkika, E.; Hass, P.; Henkenberens, C.; Herold, H.-U.; et al. Long-term Follow-up and Patterns of Recurrence of Patients with Oligometastatic NSCLC Treated With Pulmonary SBRT. Clin. Lung Cancer 2019, 20, e667-e677. [CrossRef]

5. Pasalic, D.; Lu, Y.; Betancourt-Cuellar, S.L.; Taku, N.; Mesko, S.M.; Bagley, A.F.; Chance, W.W.; Allen, P.K.; Tang, C.; Antonoff, M.B.; et al. Stereotactic ablative radiation therapy for pulmonary metastases: Improving overall survival and identifying subgroups at high risk of local failure. Radiother. Oncol. 2020, 145, 178-185. [CrossRef]

6. Bezjak, A.; Paulus, R.; Gaspar, L.E.; Timmerman, R.D.; Straube, W.L.; Ryan, W.F.; Garces, Y.I.; Pu, A.T.; Singh, A.K.; Videtic, G.M.; et al. Safety and Efficacy of a Five-Fraction Stereotactic Body Radiotherapy Schedule for Centrally Located Non-Small-Cell Lung Cancer: NRG Oncology/RTOG 0813 Trial. J. Clin. Oncol. 2019, 37, 1316-1325. [CrossRef]

7. Song, S.Y.; Choi, W.; Shin, S.S.; Lee, S.-W.; Ahn, S.D.; Kim, J.H.; Je, H.U.; Park, C.I.; Lee, J.S.; Choi, E.K. Fractionated stereotactic body radiation therapy for medically inoperable stage I lung cancer adjacent to central large bronchus. Lung Cancer 2009, 66, 89-93. [CrossRef]

8. Haseltine, J.M.; Rimner, A.; Gelblum, D.Y.; Modh, A.; Rosenzweig, K.E.; Jackson, A.; Yorke, E.D.; Wu, A.J. Fatal complications after stereotactic body radiation therapy for central lung tumors abutting the proximal bronchial tree. Pr. Radiat. Oncol. 2016, 6, e27-e33. [CrossRef]

9. Murrell, D.H.; Labe, J.; Erickson, A.; Millman, B.; Palma, D.A.; Louie, A.V. Stereotactic ablative radiotherapy for ultra-central lung tumors: Prioritize target coverage or organs at risk? Radiat. Oncol. 2018, $13,57$. [CrossRef]

10. Tekatli, H.; Haasbeek, N.; Dahele, M.; De Haan, P.; Verbakel, W.; Bongers, E.; Hashemi, S.; Nossent, E.; Spoelstra, F.; De Langen, A.J.; et al. Outcomes of Hypofractionated High-Dose Radiotherapy in Poor-Risk Patients with "Ultracentral" Non-Small Cell Lung Cancer. J. Thorac. Oncol. 2016, 11, 1081-1089. [CrossRef]

11. Rim, C.H.; Kim, Y.; Kim, C.Y.; Yoon, W.S.; Yang, D.S. Is stereotactic body radiotherapy for ultra-central lung tumor a feasible option? A systemic review and meta-analysis. Int. J. Radiat. Biol. 2019, 95, 329-337. [CrossRef] [PubMed]

12. Stone, B.; Mangona, V.S.; Johnson, M.D.; Ye, H.; Grills, I.S. Changes in Pulmonary Function Following Image-Guided Stereotactic Lung Radiotherapy. J. Thorac. Oncol. 2015, 10, 1762-1769. [CrossRef] [PubMed]

13. Navarro-Martin, A.; Aso, S.; Cacicedo, J.; Arnaiz, M.; Navarro, V.; Rosales, S.; De Blas, R.; Ramos, R.; Guedea, F. Phase II Trial of SBRT for Stage I NSCLC: Survival, Local Control, and Lung Function at 36 Months. J. Thorac. Oncol. 2016, 11, 1101-1111. [CrossRef] [PubMed]

14. Hörner-Rieber, J.; Dern, J.; Bernhardt, D.; König, L.; Adeberg, S.; Verma, V.; Paul, A.; Kappes, J.; Hoffmann, H.; Debus, J.; et al. Parenchymal and Functional Lung Changes after Stereotactic Body Radiotherapy for Early-Stage Non-Small Cell Lung Cancer-Experiences from a Single Institution. Front. Oncol. 2017, 7. [CrossRef]

15. Stephans, K.; Djemil, T.; Reddy, C.A.; Gajdos, S.M.; Kolar, M.; Machuzak, M.; Mazzone, P.; Videtic, G.M.M. Comprehensive Analysis of Pulmonary Function Test (PFT) Changes After Stereotactic Body Radiotherapy (SBRT) for Stage I Lung Cancer in Medically Inoperable Patients. J. Thorac. Oncol. 2009, 4, 838-844. [CrossRef] 
16. Mangona, V.S.; Aneese, A.M.; Marina, O.; Hymas, R.V.; Ionascu, D.; Robertson, J.M.; Gallardo, L.J.; Grills, I.S. Toxicity After Central versus Peripheral Lung Stereotactic Body Radiation Therapy: A Propensity Score Matched-Pair Analysis. Int. J. Radiat. Oncol. 2015, 91, 124-132. [CrossRef]

17. Henderson, M.; McGarry, R.; Yiannoutsos, C.; Fakiris, A.; Hoopes, D.; Williams, M.; Timmerman, R. Baseline Pulmonary Function as a Predictor for Survival and Decline in Pulmonary Function Over Time in Patients Undergoing Stereotactic Body Radiotherapy for the Treatment of Stage I Non-Small-Cell Lung Cancer. Int. J. Radiat. Oncol. 2008, 72, 404-409. [CrossRef]

18. Bishawi, M.; Kim, B.; Moore, W.H.; Bilfinger, T. Pulmonary Function Testing After Stereotactic Body Radiotherapy to the Lung. Int. J. Radiat. Oncol. 2012, 82, e107-e110. [CrossRef]

19. Stanic, S.; Paulus, R.; Timmerman, R.D.; Michalski, J.M.; Barriger, R.B.; Bezjak, A.; Videtic, G.M.; Bradley, J. No Clinically Significant Changes in Pulmonary Function Following Stereotactic Body Radiation Therapy for Early- Stage Peripheral Non-Small Cell Lung Cancer: An Analysis of RTOG 0236. Int. J. Radiat. Oncol. 2014, 88, 1092-1099. [CrossRef]

20. Guckenberger, M.; Klement, R.J.; Kestin, L.L.; Hope, A.J.; Belderbos, J.; Werner-Wasik, M.; Yan, D.; Sonke, J.-J.; Bissonnette, J.-P.; Xiao, Y.; et al. Lack of a Dose-Effect Relationship for Pulmonary Function Changes After Stereotactic Body Radiation Therapy for Early-Stage Non-Small Cell Lung Cancer. Int. J. Radiat. Oncol. 2013, 85, 1074-1081. [CrossRef]

21. Alberts, L.; El Sharouni, S.Y.; Hofman, F.N.; Van Putte, B.P.; Tromp, E.; Van Vulpen, M.; A Kastelijn, E.; Schramel, F.M.N.H. Changes in Pulmonary Function After Stereotactic Body Radiotherapy and After Surgery for Stage I and II Non-small Cell Lung Cancer, a Description of Two Cohorts. Anticancer. Res. 2015, 35.

22. Hanna, G.; Murray, L.; Patel, R.; Jain, S.; Aitken, K.; Franks, K.; Van As, N.; Tree, A.; Hatfield, P.; Harrow, S.; et al. UK Consensus on Normal Tissue Dose Constraints for Stereotactic Radiotherapy. Clin. Oncol. 2018, 30, 5-14. [CrossRef] [PubMed]

23. Quanjer, P.H.; Stanojevic, S.; Cole, T.J.; Baur, X.; Hall, G.L.; Culver, B.H.; Enright, P.L.; Hankinson, J.L.; Ip, M.S.; Zheng, J.; et al. Multi-ethnic reference values for spirometry for the 3-95-yr age range: The global lung function 2012 equations. Eur. Respir. J. 2012, 40, 1324-1343. [CrossRef] [PubMed]

(C) 2020 by the authors. Licensee MDPI, Basel, Switzerland. This article is an open access article distributed under the terms and conditions of the Creative Commons Attribution (CC BY) license (http://creativecommons.org/licenses/by/4.0/). 